\title{
Permanent trading impacts and bond yields
}

Article

Accepted Version

Dufour, A. and Nguyen, M. (2012) Permanent trading impacts and bond yields. European Journal of Finance, 18 (9). pp. 841 864. ISSN 1466-4364 doi:

https://doi.org/10.1080/1351847X.2011.601639 Available at https://centaur.reading.ac.uk/26482/

It is advisable to refer to the publisher's version if you intend to cite from the work. See Guidance on citing.

Published version at: http://www.tandfonline.com/doi/abs/10.1080/1351847X.2011.601639

To link to this article DOI: http://dx.doi.org/10.1080/1351847X.2011.601639

Publisher: Taylor and Francis

All outputs in CentAUR are protected by Intellectual Property Rights law, including copyright law. Copyright and IPR is retained by the creators or other copyright holders. Terms and conditions for use of this material are defined in the End User Agreement.

\section{www.reading.ac.uk/centaur}

\section{CentAUR}

Central Archive at the University of Reading

Reading's research outputs online 


\title{
Permanent Trading Impacts and Bond Yields
}

\author{
Alfonso Dufour \\ ICMA Centre, University of Reading \\ Minh Nguyen \\ Bradford University School of Management
}

April 2011

We analyze four years of transaction data for euro-area sovereign bonds traded on the MTS electronic platforms. In order to measure the informational content of trading activity, we estimate the permanent price response to trades. We find not only strong evidence of information asymmetry in sovereign bond markets, but we also show the relevance of information asymmetry in explaining the cross-sectional variations of bond yields across a wide range of bond maturities and countries. Our results confirm that trades of more recently issued bonds and longer maturity bonds have a greater permanent effect on prices. We compare the price impact of trades for bonds across different maturity categories and find that trades of French and German bonds have the highest long-term price impact in the short maturity class whereas trades of German bonds have the highest permanent price impacts in the long maturity class. More importantly, we study the cross-section of bond yields and find that after controlling for conventional factors, investors demand higher yields for bonds with larger permanent trading impact. Interestingly, when investors face increased market uncertainty, they require even higher compensation for information asymmetry.

Keywords: Bond markets, Liquidity, Information asymmetry, Credit Risk

JEL Classification: G12, G14, G15, H81 


\section{Introduction}

Recent advances in financial economics have emphasized that market players are asymmetrically informed about asset values and that financial market transactions may convey private information about fundamental values. Moreover, the level of information asymmetry varies across securities (Hasbrouck, 1991a; Hasbrouck, 1991b) and with market conditions (Dufour and Engle, 2000). Although most empirical studies examine equity markets, there is a growing consensus on the relevance of asymmetric information in other markets as well. For instance, considering the origins of the 2007 subprime-mortgage market crisis, Calomiris (2009) claims that asymmetric information has crucially affected credit spreads. More importantly for our study, information asymmetry seems to be relevant even when market participants may fully agree on the future notional cash flows of a security, such as in the Treasury market (Brandt and Kavajecz, 2004; Pasquariello and Vega, 2007).

In this paper, we evaluate the empirical relevance of information asymmetry in the euro-area sovereign bond markets. In particular, we examine the significance of information asymmetry across a wide range of bond maturities and countries, assess the impact of information asymmetry on bond yields and study how this impact changes during times of higher market uncertainty. Our focus is on Treasury securities not only due to their traditional role in the investment universe but also due to their use in pricing and hedging other financial instruments. ${ }^{1}$

Empirical research provides evidence consistent with at least two explanations for the existence of asymmetric information in the Treasury markets. The first conjecture is based on the concept of heterogeneous private information, namely investors have differential abilities to interpret past economic data or to understand 
the current state of economy (Balduzzi et al., 2001; Brandt and Kavajecz, 2004; Green, 2004). It seems reasonable to assume that sophisticated investors such as hedge funds or proprietary trading desks at investment banks have more sophisticated and powerful models to estimate the effects of changes in economic fundamentals onto the yield curve than a typical investor. The second conjecture assumes that information asymmetry arises because a subset of market participants, such as large banks, privately observe their clients' net order flow and use this information to forecast future prices. This argument closely follows the framework described by Cao et al. (2006) for the foreign exchange market. Peiers (1997) provides evidence that Deutsche Bank is the price leader in the markets for the Deutsche Mark/U.S. Dollar exchange rate prior to the German central bank interventions. Ito et al. (1998) show that Japanese banks are perceived as informed traders in the Yen currency markets. In particular, dealers in the foreign exchange markets are convinced that players with large customer bases obtain privileged information about their customers' orders which gives them a competitive advantage (Cheung and Wong, 2000).

Market participants are ultimately interested in understanding whether and how information asymmetry affects security prices and returns. Financial theory suggests that risk-sharing limitations may lead to the emergence of asymmetric information risk premia (Wang, 1993; O'Hara, 2003; Garleanu and Pedersen, 2004). On average, uninformed traders lose when trading in markets characterised by the presence of traders with superior information. O'Hara (2003) argues that this information disadvantage cannot be fully diversified away by holding the market portfolio. Consequently, cross-sectional security return differentials arise because uninformed traders require additional compensation for holding securities subject to greater informational asymmetry. 
Our analysis is similar to the study by Li et al. (2009) which shows that asymmetric information helps explain the variations in returns across U.S. government bonds. We consider whether the same results hold in the context of the euro-zone treasury markets. Compared to their U.S. counterpart, the European Treasury markets remain much more heterogeneous in terms of the credit worthiness of the issuers, the maturity spectrum, the issuance amount and the trading mechanism. The data for our empirical analysis are provided by MTS which executes a significant share of the wholesale sovereign bond transactions in Europe on its electronic trading platforms. $^{2}$ Dealers operating on the MTS markets are required to provide two-sided quotes for a minimum size, a maximum spread and a minimum number of hours during the trading day. Details of quotes and executed trades are recorded and transmitted in real-time to the rest of the market or to information providers like Bloomberg or Reuters. Given the specific institutional features characterising the euro-zone bond markets, we are interested in investigating whether information asymmetry remains relevant in a transparent electronic market with explicit market making obligations. Since the same monetary policies and interest rate decisions from the European Central Bank directly affect all the euro-zone markets, privately informed traders enjoy a greater opportunity set to exploit their information advantages. We study whether information from bond trading activity is eventually incorporated into prices and investigate which sovereign bond market shows greater informational asymmetry.

We employ the methodology developed by Hasbrouck (1991a) to identify and measure the informational impact of order flow on prices. Clearly, the impact of trades on prices is affected by both liquidity and asymmetric information (see also Chordia et al., 2002). To separate these liquidity and informational effects of bond 
trades, we assume that liquidity effects are transient whereas informational effects are permanent. Hence, we estimate informational effects using the long-term price response to the unexpected component of a bond trade. To facilitate comparability amongst securities, we construct the series of quotes and transactions sampled with a fixed time interval and measure the persistent price impact over a sufficiently long period of time, which we assume to be one hour. For the U.S. Treasury market Green (2004) estimates that it takes less than fifteen minutes for the effect of trade innovations to be fully impounded into prices.

We begin our empirical investigation by estimating the level of asymmetric information in euro-area bond markets and then we study the variations of information asymmetry across bond maturities and across countries. We find that Treasury bond transactions induce permanent price changes. Hence our evidence is consistent with an informational role of Treasury market trades. When considering bonds within the same maturity group, we find that trades for the most recently-issued bonds have larger permanent price effects. Consistent with Admati and Pfleiderer (1988), informed traders facing parallel markets would trade in the most liquid markets, i.e. the on-the-run segment, to disguise their trading and reduce their execution costs. While trades for both French and German bonds generate the largest permanent changes for the short maturity bond category, the impact of German bond trades clearly dominates in the long maturity bond category. Our findings indicate significant cross-sectional differences amongst euro-area countries in the information content of bond transactions and therefore in the level of information asymmetry.

Although the above results are obtained after controlling for the average trade size, we recognise that other factors may affect the cross-sectional comparison of permanent trade impacts. Therefore, we propose a cross-sectional model that controls 
also for the behaviour of the term structure of interest rates, credit quality and microstructure features such as liquidity, tick size and number of market participants. Our analysis strongly supports the conjecture that investors demand compensation for information asymmetry. Bond yields are significantly and positively related to permanent trading impacts after controlling for conventional yield determinants such as the behaviours of the term structure of interest rates, credit quality and liquidity. In addition, this relation between yields and permanent trading impacts varies over time and becomes more pronounced during periods of elevated market uncertainty. Our findings suggest that when volatility in either the equity or bond market increases, investors become significantly more sensitive to adverse selection risk and require much higher returns for holding bonds with higher permanent trading impact.

The remainder of this paper is organized as follows. Section 2 describes the data used for the analysis while Section 3 discusses the empirical methodology. Section 4 presents the empirical results and Section 5 provides some conclusions.

\section{Data}

We use transaction data from the MTS Time Series database. MTS is a major wholesale electronic market for trading fixed-income securities in Europe. Details about the data and the institutional characteristics of the MTS markets can be found in

(Dufour and Skinner, 2004; Dufour and Nguyen, 2008). ${ }^{3}$ Our sample covers the period from the first available date in the dataset April 1, 2003 to September 28, 2007. We focus on ten euro-area sovereign bond markets including Austria, Belgium, Finland, France, Germany, Greece, Italy, the Netherlands, Portugal and Spain. We only select bonds issued by central governments in the euro currency. The bonds must be fixed-rate coupon bonds or zero-coupon bonds with at least six months and less than thirty years of remaining time to maturity. ${ }^{4}$ We exclude from our sample quasi- 
government bonds, bonds with special fixed-income features such as floating rate coupons, coupon-stripped, inflation- or index-linked bonds, securities traded prior to issue and when-issued securities. There are up to 375 sovereign bonds in the final sample.

Our data includes details of quotes and transactions which are electronically recorded with time stamps precise to the millisecond. For each transaction, we have information on the price, the quantity traded as well as whether the trade was initiated by a buyer or a seller. For each quote revision, our data contain the best three levels of bid and ask prices with their associated quantities. In this study, we focus on the top bid and ask quotes and keep only those posted within the MTS official trading hours (8:15am-5:30pm Central European Time).

The MTS dataset also contains daily summary measures of trading activity for bonds traded on the MTS platforms. These measures include the modified duration, the daily average spread and the daily trading volume. In addition, the data provide daily updates on the number of traders enabled to trade a particular bond through a certain platform and the number of market makers with obligations to post bid and ask quotes on that same platform. Finally, the MTS-Time Series database provides the daily yield midpoint computed using the most recent valid quote before 5:00pm Central European Time and details about the characteristics of the various bonds including coupon rates and tick sizes.

We supplement the MTS data with credit rating data from Markit. ${ }^{5}$ The ratings provide an independent assessment of the credit worthiness of the central governments to repay the interest plus the principal. Our bonds are rated by at least one of the rating agencies including Standard \& Poor's, Moody's and Fitch. If a bond 
receives multiple ratings, we keep the lowest rating to be conservative. We have the monthly time series of ratings for each bond in the sample.

[Insert Table 1 about here]

Table 1 presents the descriptive statistics of our data. Our bonds can be classified into three credit rating categories: AAA, AA and A. These sovereign ratings remain stable over the whole sample period with two exceptions: Spain was upgraded from AA to AAA in January 2005, while Italy was downgraded from AA to A in November 2006. Germany accounts for the largest number of bonds in the sample and the highest number of daily observations. However, Italian bonds record the highest number of transactions and account for the majority of the trading volume on the MTS markets. This pattern arises because most of the trading activity for Italian sovereign bonds concentrates on the MTS markets, while transactions of bonds of other countries are more dispersed and fragmented. The average trade size ranges from 5.55 million euro for the Italian bonds to 9.46 million euro for the Finnish bonds. Italy and Spain tend to have longer maturity bonds while Finland has shorter maturity bonds.

\section{Empirical Methodology}

As a measure of asymmetric information we focus on the permanent trading impact or the persistent price response to an unexpected transaction. Obviously, we need to separate the informational effect of trading activity from the temporary liquidity effect. First, we identify and measure the permanent price effect. Second, we compute a number of liquidity measures which are used to control for the microstructure effects in the cross-sectional analysis. Finally, we consider the Nelson-Siegel parametric model to account for the term structure of interest rates. 


\subsection{Permanent trading impacts}

Our method closely parallels the framework introduced by Hasbrouck (1991a) to capture trade informativeness. In the market microstructure literature, transactions are important because they convey information about security fundamentals that markets need to aggregate. Hence the arrival of a trade induces dealers to revise their beliefs on fundamental values, causes their inventory to depart from their desired inventory levels and forces them to adjust prices accordingly. Because the inventory effects are inherently transient, Hasbrouck (1991a) suggests that the information content of a trade should be measured by its long-term, permanent impact on prices.

Let $q_{\mathrm{t}}$ denote the midpoint of the prevailing bid and ask quotes posted by a dealer who stands ready to buy from and sell to other market participants and $t$ is the sampling time indicator. Let $x_{\mathrm{t}}$ denote the net aggregate buy and sell volume for all the trades executed between times $t-1$ and $t$. Thus, the quote return $r_{\mathrm{t}}=\ln \left(q_{\mathrm{t}}\right)-\ln \left(q_{\mathrm{t}-1}\right)$ reflects the dealer's response to the net order flow $x_{\mathrm{t}}$. We analyze the dynamics of the quote changes and the net order flows using a Vector Autoregressive (VAR) model described as:

$$
\begin{gathered}
r_{t}=\sum_{j=1}^{m} a_{j} r_{t-j}+b_{0} x_{t}+\sum_{i=1}^{m} b_{i} x_{t-i}+v_{1 t}, \\
x_{t}=\sum_{j=1}^{m} c_{j} r_{t-j}+\sum_{i=1}^{m} d_{i} x_{t-i}+v_{2 t},
\end{gathered}
$$

where $v_{1 \mathrm{t}}$ is the quote change innovation, $m$ is the order of lags in the autoregerssion while $a$ 's, $b$ 's, $c^{\prime}$ 's, $d$ 's are the coefficients. In this specification, the disturbance $v_{2 \mathrm{t}}$ is the unexpected component of the order flow or the trade innovation. The dynamics of the order flow can be predicted using equation (2) above hence any private information conveyed by the trades must be captured by $v_{2 \mathrm{t}}$. The coefficient $b_{0}$ 
measures the immediate price response to the trade. Several researchers use this coefficient to estimate the information effects of the transactions (e.g. Brennan and Subrahmanayam, 1996; Brandt and Kavajecz, 2004). As explained in Chordia et al. (2002), this coefficient cannot be a good proxy for asymmetric information because it is potentially influenced by both permanent and transitory effects of transactions. Hasbrouck (1991a) suggests measuring asymmetric information by calculating the cumulative impulse response to a shock to the order flow equation. This can be easily computed using the Vector Moving Average (VMA) representation:

$$
\left[\begin{array}{l}
r_{t} \\
x_{t}
\end{array}\right]=\left[\begin{array}{ll}
\alpha(L) & \beta(L) \\
\gamma(L) & \delta(L)
\end{array}\right]\left[\begin{array}{l}
v_{1 t} \\
v_{2 t}
\end{array}\right],
$$

where $L$ is the lag operator. The impact of the unexpected component of a trade on quotes after $k$ periods, $r_{\mathrm{t}+\mathrm{k}}^{x}$, is obtained by taking the sum of the coefficients of the impulse response function:

$$
r_{t+k}^{x}=\sum_{i=0}^{k} \beta_{i} v_{2 t}
$$

In the previous literature, the time indicator $t$ is often an event counter, i.e. $t$ is incremented whenever a trade occurs or a quote is revised. However, since trading intensity as well as the frequency of quote updates typically differ across securities, this indicator becomes less useful when we consider a cross-sectional analysis. To facilitate comparability across securities, Hasbrouck (2007) suggests that the VAR should be estimated in calendar time, i.e. $t$ denotes a fixed time interval. In this study, we choose a sampling interval of ten seconds. This choice of sampling time interval balances the need for frequent quote updates in order to carefully track price dynamics and the need of reducing the transitory microstructure effects. For every ten second interval of the trading day, we save the prevailing quotes and the aggregate order flow and hence obtain time series of quotes and trades. This is repeated for each bond in 
our sample. We apply VAR models to the time series of quote changes and trades and compute the persistent impact of an average trade shock for each bond over an hour horizon. Our choice of $k$ is consistent with Green (2004) who shows that it takes less than fifteen minutes in the U.S. Treasury markets for new trade related information to be incorporated into prices. Therefore, by allowing a sufficiently large $k$, we ensure that the cumulative price change fully reflects the revision in the efficient prices caused by the trade innovation.

Bonds have different average trade sizes, and in order to be able to compare estimated permanent trading impacts across bonds, we need to control for these differences in average trade size. Consequently, we scale the signed trade quantity $x_{\mathrm{t}}$ by the average trade size over the estimation window. The VAR estimation also requires the specification of an appropriate number of lags $m$. If the sampling time is small, allowing for lagged effects over even a reasonably short span of clock time leads to an extremely large number of coefficients to be estimated. We follow Hasbrouck (2003) and use polynomial distributed lags to reduce the number of parameters in the VAR.

We estimate the VAR for each bond over a six month period. This choice of the estimation window is comparable to the one that Hasbrouck (1991a) uses to analyze NYSE stocks and Li et al. (2009) employ to examine U.S. Treasury securities. To obtain stable estimates, we exclude bonds that have fewer than thirty days with at least one trade over the estimation window. We discard overnight price changes to avoid price contaminations due to overnight news arrival. Due to the complexity of the VAR estimation output, it is easier to study the dynamics of quote changes and order flow by considering the cumulative impulse response functions.

[Insert Figure 1 about here] 
Figure 1 illustrates the price response to a trade innovation for the most recently issued 10-year bonds from Germany, France, Italy and Spain available in April 2003. The impulse response functions are constructed by assuming that at $t=0$, the system for each bond is in equilibrium until it is shocked by an unexpected buy order with an average trade size. We track how this shock propagates and compute the cumulative quote change at every subsequent time interval. In general, we observe that quote revisions reach a permanent level within six minutes. More importantly, these persistent levels are greater than zero and differ across securities. For instance, an unexpected buy order leads to a cumulative quote change of 0.7 basis points for the German bond, but for the Italian bond the cumulative quote change is merely 0.35 basis points. Trades for bonds of different countries have different impacts on prices and hence are differently informative.

\subsection{Measures of liquidity}

For the cross-sectional analysis, we need to further control for non-information components of trading activity by computing measures of liquidity. The most popular liquidity proxy is the bid-ask spread which measures the round-trip cost of executing small trades. Amihud and Mendelson (1991) suggest that the bid-ask spread, the sum of buying cost and selling discount for immediate execution, is the natural measure of transaction costs. Fleming (2001) finds that the bid-ask spread is a good liquidity measure in the Treasury markets because its variations consistently capture the changes in market liquidity.

We use the intraday quote data to compute the bid-ask spread for each bond on a daily basis. In particular, we compute the difference between ask and bid quotes, divide it by the spread midpoint and take the average over all best quote revisions for day d. However, rather than treating quote updates equally, we weight each spread by 
the time it remains valid in order to reduce the effect of extreme intraday quotes which may last very briefly, especially at the opening and at the closing of a trading session. Our time-weighted proportional bid-ask spread is computed as:

$$
S p r_{d}=\sum_{i=1}^{N_{d}}\left(\frac{\text { Ask }_{i}-\text { Bid }_{i}}{\left(\text { Ask }_{i}+\text { Bid }_{i}\right) / 2}\right) \frac{\text { Duration }_{i+1}}{\text { TotalTime }_{d}}
$$

where $B i d_{i}$ and $A s k_{i}$ are the $i^{t h}$ bid and ask quote revisions; Duration $_{i+1}$ is the time in seconds that the $i^{\text {th }}$ quote remains effective, specifically the time between the $i^{\text {th }}$ and the $(i+1)^{t h}$ quote revisions; TotalTime is $_{\text {is }}$ the time from the first quote after the MTS markets open at 8:15am to the closing time at 5:30pm for day $d$ and $N_{d}$ is the total number of revisions to the best quotes for day $d$.

As discussed above, the quoted spread provides a good proxy for the cost of executing small trades (see Malz, 2003). However, large institutional traders have to execute large size trades and hence are often more concerned with the depth rather than the bid-ask spread of the market. Clearly, this issue is particularly relevant for the inter-dealer Treasury market we study. Therefore, we consider the quoted depth as an additional liquidity measure. The quoted depth indicates the quantity that a market maker is willing to immediately buy from and sell to other market participants. We measure quoted depth as the average of the number of bonds available at the best bid and ask quotes.

More formally, let BidSize $_{i}$ and AskSize $_{i}$ denote the quantity of bonds in terms of nominal value available for trading at the best bid and ask quotes, respectively. Our time-weighted average market depth is computed daily for each bond from the intraday quote data as:

$$
\text { Dep }_{d}=\sum_{i=1}^{N_{d}}\left(\frac{\text { AskSize }_{i}+\text { BidSize }_{i}}{2}\right) \frac{\text { Duration }_{i+1}}{\text { TotalTime }_{d}}
$$


where BidSize $_{i}$ and AskSize $_{i}$ are the sizes available at the $i^{\text {th }}$ bid and ask quotes, Duration $_{i+1}$, TotalTime $_{d}$ and $N_{d}$ are defined as for the time-weighted bid-ask spread, $S p r_{d}$

Table 2 presents the descriptive statistics for sovereign bonds in the euro area. Instead of pooling all sovereign markets across maturities, we present them separately based on the duration of bonds. In particular, first we classify bonds into ten sovereign markets based on the nationality of the issuer. For each sovereign market, we divide the sample period in 6-month sub-periods. At the beginning of each sub-period, we rank bonds by duration. Bonds in the bottom 30 percentile are classified as short maturity bonds, bonds in the top 30 percentile are classified as long maturity bonds and all remaining bonds are classified as medium maturity bonds. Henceforth, we will refer to this classification procedure as using the 30:40:30 breakpoints of the ranked durations.

This classification provides preliminary evidence consistent with asymmetric information varying with respect to both the nationality of the issuer and the segment of the yield curve to which the bonds belong. A proper test for this issue is presented in section 4.1 below. As expected, German bonds tend to post the lowest yields while Greek bonds tend to have the highest yields. There are some exceptions with Finnish and Italian bonds showing the highest average yields in the short and long maturity groups respectively. This can be explained by the fact that these bonds also have the highest average durations in their respective groups. Italian bonds tend to be more liquid with lower bid-ask spreads and higher depths, especially at the short and medium maturities. Austrian, French and Greek bonds register higher average permanent trading impacts for the short maturity group while German bonds have higher permanent trading impacts in the medium and long maturity groups. 
[Insert Table 2 about here]

Table 3 illustrates the cross-sectional correlations of the permanent trading impacts and other bond characteristics. Permanent trading impacts are positively related to the bid-ask spread and negatively related to the market depth. In particular, liquidity strongly decreases with bond duration. The correlation coefficients of duration with the bid-ask spread and with the depth are 0.88 and -0.53 , respectively. This indicates that longer maturity bonds tend be less liquid. In addition, duration is also positively related to permanent trading impacts and the tick size. The presence of significant correlations between duration and microstructure variables may lead to collinearity problems if duration and liquidity measures are used as explanatory variables in the same regression. This observation is relevant for the asset pricing analysis conducted in section 4.2 below.

[Insert Table 3 about here]

\subsection{Nelson and Siegel's yield curve}

We aim to control for the behaviour of the term structure of interest rates and hence bond duration in our cross-sectional analysis. Empirical papers (e.g. Dunne et al., 2007; Dufour and Nguyen, 2008) indicate that no single sovereign market serves as a benchmark for all maturities in the euro-areas. Consequently, we refrain from treating a specific country as a benchmark or analyzing the term structure of interest rates for all sovereign countries. Instead, we consider the swap curve as the reference curve, a procedure which has become increasingly common in the recent literature (e.g. Blanco et al., 2005; Houweling et al., 2005; Beber et al., 2009). It is argued that although swap rates inherently embed counter-party default risk, the swap curve has several advantages over the government bond yield curve including the existence of a 
single swap curve in the euro area and the fact that swap rates are not subject to different tax treatments and repo specialness.

We obtain the euro fixed-leg swap rates from Bloomberg for fifteen different constant maturities: $1,2,3,4,5,6,7,8,9,10,12,15,20,25$ and 30 years. To analyze the term structure of the swap rates, we follow Nelson and Siegel's (1987) parametric model that specifies the spot rates, $z_{T T M}$ as:

$$
z_{T T M}=\beta_{0}+\left(\beta_{1}+\beta_{2}\right)\left[1-\frac{1-e^{\frac{-T T M}{\tau}}}{T T M / \tau}\right]-\beta_{2} e^{\frac{-T T M}{\tau}},
$$

where TTM is the term to maturity, $\beta_{i}$ and $\tau$ are the parameters to be estimated. We estimate the Nelson and Siegel's model on daily basis by minimizing the squared errors between the predicted and observed swap rates. We then calculate the swap spread defined as the difference between the sovereign bond yield and the corresponding spot rate by matching the duration of the bond with the estimated term structure of the swap rates.

\section{Empirical results}

We first study the variations in asymmetric information across euro-area Treasury markets by studying the cross-sectional differences in the informational content of bond transactions. We then examine whether information asymmetry matters in explaining the variations of bond yields. We also consider the empirical relevance of credit quality, liquidity and information asymmetry during periods of abnormal market movements. We finally analyze the robustness of our results with respect to the errors-in-variables problems in our estimation. 


\subsection{The information content of bond trades}

In traditional economic paradigms, transactions have no role in the determination of asset prices. Prices are assumed to fully reflect the economic fundamentals of the assets. The arrival of new information about the aggregate demand or supply leads to instantaneous changes in the prices at which market participants remain indifferent. However, if prices are not fully revealing, privately informed traders transact to exploit their informational advantage. Hence, transactions convey non-public information and cause prices to change. Because these trading impacts are also potentially influenced by transient liquidity effects, we consider the long-term price response to trades in order to capture the informational content of trading activity.

After estimating the level of informational asymmetry for each sample bond we study the nature of asymmetric information in our sovereign bond markets and investigate whether our data is consistent with previous empirical findings. The previous literature indicates a close relationship between the information content of Treasury securities and their seasonedness or the time since they were first issued. When a new bond is issued it is called the on-the-run bond and all the bonds previously issued with the same original maturity become off-the-run bonds. The general consensus (e.g. Amihud and Mendelson, 1991; Fleming, 2001; Krishnamurthy, 2002) is that old bonds tend be less liquid and require higher transaction costs than on-the-run bonds. In addition, lower liquidity is often associated with lack of trading activity and stale quotes. Admati and Pfleiderer (1988) explain this empirical evidence by conjecturing that informed traders facing parallel markets would trade in the more liquid markets to reduce their costs of trading. Consequently, trades of off-the-run bonds tend to be less informative than those of on-the-run bonds. Brandt and Kavajecz (2004) show that price discovery in the Treasury markets occurs 
in the on-the-run segment. Li et al. (2009) provide evidence that on-the-run bonds exhibit a higher probability of informed trading (PIN) than off-the-run bonds.

We split our sample into six month windows and, at the beginning of every window, we sort our sample bonds in terms of how recently they have been issued and form three distinct categories of seasonedness: on-the-run, just-off-the-run and off-the-run. This classification is performed for bonds belonging to various maturity buckets: 2 (1-2 years), 5 (2-5 years), 10 (5-10 years), 15 (10-15 years), 20 (15-20 years) and 30 (20-30 years). For each maturity bucket, the on-the-run group includes bonds that have been classified as the most recently-issued bonds within the previous six month window. Furthermore, just-off-the-run bonds have between six months and two years from the issue date whereas off-the-run bonds have more than two years from the issue date. The VAR models are estimated over these six month windows.

[Insert Table 4 about here]

Table 4 (Panel A) presents the average permanent trading impact for each seasonedness group within each maturity bucket. We observe that the on-the-run group for all maturity buckets tends to register higher trading impacts than the other groups. Figure 2 shows the cumulative distribution of the permanent trading impacts for each of the three seasonedness groups. The trading impacts generally increase when moving from the off-the-run group to the just-off-the-run group and finally to the on-the-run group.

[Insert Figure 2 about here]

Similarly to Li et al. (2009), we perform the Kruskal-Wallis test and the Wilcoxon rank-sum test to examine the significance of these cross-sectional differences in the permanent trading impacts. The Kruskal-Wallis test examines the null hypothesis that the trading impacts of all bond groups are drawn from the same 
distribution. The Wilcoxon rank-sum test investigates the null hypothesis that the difference between the median price impacts of two sample groups is zero versus the alternative hypothesis that one group has higher median price impact. Panel B of Table 4 presents the test statistics and the corresponding p-values. The Kruskal-Wallis test statistic suggests that the null hypothesis of identical distribution is strongly rejected. The Wilcoxon test statistics indicate that the on-the-run bonds have significantly higher trading impacts than the just-off-the-run bonds which in turn show significantly higher permanent trading impacts than the off-the-run bonds. These results show that trades for on-the-run bonds are more informative than trades of other bonds and are consistent with evidence provided by Brandt and Kavajecz (2004) and Li et al. (2009).

We then turn our attention to cross-country differences in the permanent trading impacts. Market participants observe that different euro-area countries contribute differently to the price discovery process of the various segments of the euro yield curve. In particular, the International Monetary Fund (IMF, 2001) documents that French bonds at short maturities benefit from active French money markets while the German market prevails at the longer maturities due to the presence of liquid German Bund futures markets. Dufour and Nguyen (2008) provide evidence for the price leadership of the French market in the short maturity bond category and the German market in the medium and long maturity bond categories.

To examine differences in sovereign bond informativeness, we use the same procedure as above and consider six-month sub-periods. At the beginning of every sub-period, first we sort all sample bonds by their durations and then classify them into three maturity groups (short, medium and long) using the usual 30:40:30 breakpoints of the ranked duration. For brevity, we focus on the sovereign bonds from 
Germany, France, Italy and Spain. The European Central Bank (ECB, 2004) suggests that these four markets in total account for more than $78 \%$ of the outstanding amount in the euro-area.

[Insert Figure 3 about here]

Panel A of Figure 3 illustrates the cumulative distributions of the permanent trading impacts for the short maturity group. While the French bonds fare closely to the German, they tend to exhibit higher trading impacts than the Italian and the Spanish bonds. The Kruskal-Wallis test statistic in Panel A of Table 5 significantly rejects the null hypothesis that these countries share the same distribution of the permanent trading impacts. The pair-wise Wilcoxon test statistics show that although the French bonds do not register significantly higher trading impacts than the German bonds, their impacts are strongly larger than those of the Italian and marginally higher than those of the Spanish bonds.

[Insert Table 5 about here]

Panel B of Figure 3 exhibits the cumulative distributions of trading impacts for the medium maturity group. We notice that the German market tends to register higher trading impacts. Again, in Panel B of Table 5, the Kruskal-Wallis test statistic rejects the null hypothesis of identical distributions. However, pair-wise comparisons using the Wilcoxon test show that the impacts of German, French and Spanish bonds are not statistically different; whereas Italian bonds have significantly lower trading impacts.

The cross-country differences in permanent trading impacts are most clearly demonstrated in Panel $\mathrm{C}$ of Figure 3. In the he long maturity group, the trading impacts of the German bonds are clearly larger than those of other euro-area 
countries. In Panel $\mathrm{C}$ of Table 5, Kruskal-Wallis test statistic also rejects the null hypothesis of identical distributions. The Wilcoxon test statistics show that the German bonds have significantly higher trading impacts than the other sovereign bonds. Consistent with past research, these results suggest significant cross-sectional differences among euro-area countries in the informational content of bond transactions.

\subsection{Cross-sectional regressions}

Having established the presence of asymmetric information in the euro-area Treasury markets, we examine whether information asymmetry matters in explaining the cross-sectional differences in expected bond returns. Similarly to Houweling et al. (2005), we consider bond yields instead of returns because bond yields are a better proxy for the expected returns than realized returns. In the presence of asymmetric information, we predict that investors would require an extra compensation for asymmetric information risk. Consequently, bond yields will significantly increase with higher permanent trading impacts.

In our asset pricing tests, we control for other variables that potentially affect bond yields. Gebhardt et al. (2005) suggest that bond duration and credit quality matter in explaining cross-sectional bond returns. However, because duration is strongly correlated with bond liquidity measures, rather than using duration as one of the explanatory variables, we consider the swap spread as the dependent variable to control for term structure effects and avoid multicollinearity problems. Credit ratings are used as a proxy for credit quality and are included among the explanatory factors in the regression. In addition, we use the bid-ask spread and the market depth to capture the cross-sectional effects of market liquidity. We also control for tick size because larger tick sizes limit the prices that market makers can quote and, hence, 
may lead to higher transaction costs and lower market liquidity (for empirical evidence see Goldstein and Kavajecz (2000) and Bessembinder(2002)). We use the bond coupon rate to account for the effects of different tax regimes while the number of market participants serves as another control variable. We regress the swap spreads on various explanatory variables in cross-sectional regressions described as:

$$
\begin{aligned}
\text { Yield }_{i t}-\text { Swap }_{i t}= & \gamma_{0 t}+\gamma_{1 t} A A_{i t}+\gamma_{2 t} A_{i t}+\gamma_{3 t} I M P_{i t-1}+\gamma_{4 t} S P R_{i t} \\
& +\gamma_{5 t} D E P_{i t}+\gamma_{6 t} C P N_{i t}+\gamma_{7 t} T I C_{i t}+\gamma_{8 t} P A R T_{i t}+\eta_{i t}
\end{aligned}
$$

where Yield $_{\mathrm{it}}$ Swap $_{\text {it }}$ is the swap spread or the difference between bond yield and the swap rate of bond $\mathrm{i}$ at date $\mathrm{t}$. Clearly, we are particularly interested in assessing the role played by the permanent trading impact $\mathrm{IMP}_{\mathrm{t}-1}$. To avoid possible endogeneity problems, we use the permanent trading impacts estimated over the previous six month window. Additionally, our regressors include the constant, two rating dummies $\mathrm{AA}_{\mathrm{it}}$ and $\mathrm{A}_{\mathrm{it}}$ ( $\mathrm{AA}$ equals 1 if the bond has $\mathrm{AA}$ rating and zero otherwise and A equals 1 if the bond is rated A and zero otherwise), the bid-ask spread $\mathrm{SPR}_{\mathrm{it}}$, the market depth $\mathrm{DEP}_{\mathrm{it}}$, the number of participants authorised to trade a

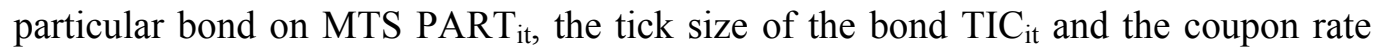
$\mathrm{CPN}_{\mathrm{it}}$. The $\gamma^{\prime} \mathrm{s}$ are the coefficients while $\eta_{\text {it }}$ is the error term.

Because the initial six month window is dedicated to the estimation of the first permanent trading impacts, we perform the cross-sectional regressions on a daily basis over the period from October 1, 2003 to September 28, 2007. The time series of the regression estimates are used for the tests of statistical significance. We adopt the Newey-West procedure to correct for heteroscedasticity and auto-correlation in these estimates. Petersen (2009) shows that the Newey-West adjusted standard errors perform better in asset pricing tests than those derived from ordinary least squares or the traditional Fama and MacBeth (1973) approach. 
[Insert Table 6 about here]

Table 6 reports the average coefficients and the Newey-West adjusted tstatistics (in parentheses) obtained from the cross-sectional regressions. We initially split the sample into two parts, one includes the AAA-rated bonds and the other includes the AA- and A-rated bonds. We then perform cross-sectional regressions on these two categories of bonds. The regression results are presented in columns 2 and 3 respectively. Next, we pool all the bonds together and show the regression results in column 4. Except for the coefficient of the market participants within the AAA category, all coefficients are significant at the one percent level. The two rating dummies $\mathrm{AA}$ and $\mathrm{A}$ are used to capture the effects of credit quality differences. In column 4, the coefficients of the credit rating dummies reflect the yield differences of the AA- and A-rated bonds relative to the AAA-rated bonds. The A dummy coefficient in column 3 indicates the yield spread between A- and AA-rated bonds. We find that bonds with higher credit quality require lower yields. On average the AA-rated bonds register a spread of 6 basis points above the AAA bonds. The yield spread between A-ated and AAA-rated bonds averages 14.3 basis points.

Our tests confirm that liquidity affects bond prices. Bond yield spreads increase with the bid-ask spread and decrease with market depth. For instance, the coefficient of the spread in Column 4 implies that a one basis point rise in the bid-ask spread will lead on average to a 0.8 basis points increase in yields, whereas one million euro increase in the tradable quantity results in a 2.3 basis points yield reduction. The coefficient of the market depth is larger and statistically more significant with the AA- and A-rated bonds than with the AAA-rated bonds, suggesting that market depth is more important with the lower rated bonds. In addition, bond yields are also positively related to the bond tick size. This result 
indicates that higher tick size imposes higher transaction costs, and consequently is associated with higher bond yields.

Surprisingly, bond yields are positively related to the number of market participants trading a particular bond. This relation is mainly relevant to the AA-A category. Therefore, a larger number of market participants is associated with higher bond yields and hence it does not necessarily mean increased bond liquidity. Nevertheless, this result could simply reflect the Italian bond effect because Italian bonds have a consistently higher number of market participants (see Table 2 and section 4.4). Additionally, bond yields are positively associated with the coupon rate. Since investors need to pay income taxes for coupon-bearing bonds, they require higher yields for higher coupon bonds.

Most importantly, we find that bonds with higher trading impacts require higher bond yields. The permanent trading impact variable has positive and significant estimated coefficients across all bond categories. These results are consistent with previous results in the equity market (Easley et al., 2002). The average adjusted R-square values range from $50 \%$ for the AAA-rated bonds to $64 \%$ for the lower rated bonds and this indicates that our variables do well in capturing the crosssectional variation of Treasury bond yields.

\subsection{Asymmetric information and high volatility periods}

After formalizing and estimating the cross-sectional relationship between asymmetric information and Treasury bond yield spreads, we examine how this relationship varies during periods of elevated market uncertainty. Our sample contains a number of extraordinary events often regarded in the financial press as "flight-to-quality" and "flight-to-liquidity" events. In particular, we consider the periods surrounding the Madrid bombing in March 2004, the London bombing in July 2005 and the beginning 
of the sub-prime mortgage crisis in August 2007. Our investigation focuses on the empirical relevance of the information asymmetry variable during these abnormal market movements.

We define the days with abnormal market uncertainty as those days when the implied volatility in the bond or equity markets is one standard deviation above the mean. The periods when this condition does not hold are simply considered as normal. First, we create two sub-samples containing the days with higher equity market volatility and higher bond market volatility respectively. Then, we run the crosssectional regressions (8) separately on each of these two sub-samples. We use the pair-wise Wilcoxon test to examine whether the average estimates obtained from the abnormal periods are significantly higher than those derived from the normal periods.

For the definition of the high equity volatility periods, we use the volatility implied from equity index options. Specifically, we employ the vStoxx index. ${ }^{6}$ This index provides market expectations of the near term volatility in the euro zone which are embedded in the option prices of the Dow Jones Euro Stoxx 50 equity index. Several researchers have recognised that the equity index implied volatility is a useful indicator for the level and the uncertainty of future volatility (e.g. Fleming, 1998; Veronesi, 1999; Blair et al., 2001; Coval and Shumway, 2001). Connolly et al. (2007) show that this measure explains return co-movements between equity and bond markets.

For the definition of high bond market volatility periods, we follow Beber et al. (2009) and consider the implied volatility obtained from the prices of swaptions, the one-month option contract on the one-year euro swap rate. From a theoretical viewpoint, volatility is positively related to the price of liquidity. Constantinides (1986) indicates that expected asset returns increase with volatility because higher 
volatility induces more frequent trading and leads to higher transaction costs. Vayanos (2004) shows that higher volatility amplifies the likelihood that fund managers fail to achieve a certain return target, become subject to fund withdrawals and, subsequently, need to incur higher transaction costs when liquidating assets.

[Insert Table 7 about here]

Table 7 presents the regression estimates for each sub-sample. We also report the differences in the estimates between the abnormal and normal sample periods and the test statistics for their significance. While the signs of the coefficients for the high volatility periods remain the same as for the normal periods, the size of the coefficients differs significantly.

Sovereign bond yields are still negatively related to credit quality. Although AAA-rated bonds continue to register lower yields than those of the AA-rated and Arated bonds, these yield differences are significantly narrowed when volatility increases. In addition, the cross-sectional differences in bond yields are more strongly related to liquidity. During periods of higher uncertainty, bonds with higher bid-ask spread or lower market depth require significantly higher yields. Consistent with Beber et al. (2009) our results indicate that liquidity is more important than credit quality in explaining the behaviour of asset prices during "flight-to-quality" and "flight-to-liquidity" events.

We find that information asymmetry has greater impact on cross-sectional bond yields during periods of extreme market uncertainty. For instance, the coefficient of the permanent trading impact variable is four times larger when equity market volatility is abnormally high than during normal periods. Interestingly, when we consider periods with different levels of interest rate volatility, the coefficient of the permanent trading impact variable is only significant for the abnormal volatility 
period. This result indicates that information asymmetry in the bond market becomes particularly relevant when market participants face increased uncertainty about the future interest rate.

\subsection{Country effects and cross-sectional bond yield variations}

Academics and market participants are often interested in exploring how country differences affect the variations of bond yields in the euro zone. To capture the country effects, we create a dummy variable for each issuing country. For example, the Italy dummy variable equals one if the observation relates to an Italian bond and zero otherwise. We replace the credit rating variables with these country dummy variables in the cross-sectional regressions. Since the German bonds serve as the benchmark in this model, the variable Italy is expected to capture the average yield spread between the German and the Italian bonds. We perform the regressions over the whole sample period from October 1, 2003 to September 28, 2007. In addition, we condition the regressions on high volatility periods in the equity and the bond markets as described in the previous section.

\section{[Insert Table 8 about here]}

Table 8 shows the estimation results for the regressions with the country dummy variables. German bonds are generally traded with the lowest yields. The spreads between German and Italian bond yields are significantly positive and, normally, average 14 basis points. These yield spreads reflect significant differences in the credit quality of the issuers. Importantly, the coefficients of the permanent impacts, the bid-ask spread and the market depth remain qualitatively unchanged. That is, investors require higher yields for information asymmetry and illiquidity. In addition, the coefficient of the market participants variable becomes economically and statistically insignificant when the country effects are included in the regressions. 
The results in this table also show the extent of time-variations in the risk premia. All the coefficients of the country dummy variables increase when either equity market or interest rate volatility increases. That is, when facing higher uncertainty investors prefer high-quality assets such as the German government bonds and, consequently, the yield spreads with respect to the German bonds increase. This is consistent with the "flight-to-quality" occurrence often described in the financial press. In addition, we also observe significant jumps in the coefficients of the permanent trading impact and the bid-ask spread. These results suggest that investors require much higher compensation for illiquidity and asymmetric information during periods of higher uncertainty.

\section{Robustness Checks}

In this section, we examine the robustness of our results by controlling for the errorsin-variables problems caused by permanent trading impacts estimated with errors. Following Black et al. (1972), we group bonds into portfolios and use the portfolio estimate as the explanatory variable. A portfolio estimate is desirable because it is highly correlated with the estimate of the individual securities and, at the same time, it is less correlated with the estimation errors.

We form bond portfolios with the following procedure. We initially sort bonds into ten sovereign markets based on the nationality of the issuers. At the beginning of each six month period, we classify bonds within each sovereign market into three maturity groups (short, medium and long) using the 30:40:30 break points of the ranked duration. As a result we obtain thirty bond portfolios at the intersection of ten sovereign markets and three maturity groups. The permanent trading impacts of bond portfolios are the equally weighted averages of the permanent trading impacts estimated for the bonds included in each portfolio. We then assign the average 
portfolio trading impact to each bond in the bond portfolio. Finally, we use these portfolio trading impacts as a dependent variable in the cross-sectional regressions estimated for each day of the following six month period. The same process is repeated for every six-month period.

\section{[Insert Table 9 about here]}

Table 9 presents the estimates of the cross-sectional regressions (8) with the portfolio permanent trading impacts. Notice that the coefficients of credit quality, liquidity measures and other bond characteristics remain similar to the coefficients presented in Table 6. Interestingly, the slopes and the $t$-statistics of the permanent trading impacts rise significantly, indicating that our original results become even stronger when we use portfolio trading impacts. Hence, after adjusting for errors-invariable problems, bonds yields remain significantly and positively related to the permanent trading impacts.

\section{Conclusion}

We analyze a cross-section of euro-area sovereign bonds traded on the MTS electronic platform from April 1, 2003 to September 28, 2007. We consider the permanent price response to the unexpected component of bond trades to capture the information content of trading activities and measure adverse selection risk. Our hypothesis is that bond yields increase with larger permanent trading impacts because investors require higher compensations for bonds subject to greater asymmetric information.

The first part of our analysis illustrates the variations of information asymmetry across maturities, across countries and over time. When we consider bonds within the same maturity category, transactions for the most recently-issued bonds generate relatively higher long-term price impacts. While trades for French and 
German bonds seem to induce the largest price revisions for short maturity bonds, the permanent effect of trades for German bonds is clearly the largest for bonds in the long maturity group. This evidence suggests significant cross-sectional differences among euro-areas countries in the information content of bond transactions. However, a proper analysis of the cross-sectional importance of asymmetric information must account for structural differences among the various euro-area Treasury markets in addition to controlling for credit quality and duration.

In the second part of our empirical analysis we run cross-sectional regressions for the yield spread and find strong evidence supporting our hypothesis that information asymmetry is priced in the Treasury markets. Bond yields are significantly and positively related to the permanent trading impacts even after controlling for the behaviour of the interest rate term structure, credit quality, liquidity and other bond characteristics. In particular, this relation varies over time and depends on market conditions. The impact of information asymmetry on bond yields is stronger during periods of increased market volatility. Our findings indicate that when facing increased uncertainty, investors require higher compensation for information asymmetry.

\section{Acknowledgements}

We are particularly grateful to the editors, Mark Salmon and Ingmar Nolte, to an anonymous referee and to Alan Huang for helpful comments and suggestions. Also, we would like to thank participants of the 41 st annual conference of the Money, Macro and Finance Research Group, at Bradford University, the 2009 conference on Individual decision making, high frequency econometrics and limit order book dynamics at Warwick University and the 2010 Eastern Finance Association Annual Meetings in Miami Beach, Florida.

\section{References}

Admati, A. R., and P. C. Pfleiderer. 1988. A theory of intraday patterns: Volume and price variability. Review of Financial Studies 1, no. 1: 3-40.

Amihud, Y., and H. Mendelson. 1991. Liquidity, maturity, and the yields on U.S. treasury securities. Journal of Finance 46, no. 4: 1411-1425. 
Balduzzi, P., E. J. Elton, and T. C. Green. 2001. Economic news and bond prices: Evidence from the U.S. treasury market. Journal of Financial and Quantitative Analysis 36, no. 4: 523-543.

Beber, A., M. W. Brandt, and K. A. Kavajecz. 2009. Flight-to-quality or flight-toliquidity? Evidence from the Euro-area bond market. Review of Financial Studies 22, no. 3: 925-957.

Bessembinder, H. 2002. Tick size, spreads, and liquidity: An analysis of Nasdaq Securities trading near ten dollars. Journal of Financial Intermediation 9, no.3: 213-239.

Black, F., M. Jensen, and M. Scholes. eds. 1972. The capital asset pricing model: Some empirical tests. New York: Praeger.

Blair, B. J., S.-H. Poon, and S. J. Taylor. 2001. Forecasting S\&P 100 volatility: The incremental information content of implied volatilities and high-frequency index returns. Journal of Econometrics 105, no. 1: 5-26.

Blanco, R., S. Brennan, and I. W. Marsh. 2005. An empirical analysis of the dynamic relation between investment-grade bonds and credit default swaps. Journal of Finance 60, no. 5: 2255-2281.

Brandt, M. W., and K. A. Kavajecz. 2004. Price discovery in the U.S. treasury market: The impact of orderflow and liquidity on the yield curve. Journal of Finance 59, no. 6: 2623-2654.

Brennan, M. J., and A. Subrahmanayam. 1996. Market microstructure and asset pricing: On the compensation for illiquidity in stock returns. Journal of Financial Economics 41, no. 3: 441-464.

Calomiris, C. W. 2009. The subprime turmoil: What's old, what's new, and what's next. Journal of Structured Finance 15, no. 1: 6-52.

Cao, H. H., M. D. Evans, and R. K. Lyons. 2006. Inventory information. Journal of Business 79, no. 1: 325-364.

Cheung, Y.-W., and C. Y.-P. Wong. 2000. A survey of market practitioners' views on exchange rate dynamics. Journal of International Economics 51, no. 2: 401419.

Chordia, T., R. Roll, and A. Subrahmanyam. 2002. Order imbalance, liquidity, and market returns. Journal of Financial Economics 65, no. 1: 111-130.

Codogno, L., C. Favero, and A. Missale. 2003. Yield spreads on EMU government bonds. Economic Policy 18, no. 37: 503-532.

Connolly, R., C. T. Stivers, and L. Sun. 2005. Stock market uncertainty and the stockbond return relation. Journal of Financial and Quantitative Analysis 40, no. 1: 161-194.

Constantinides, G. M. 1986. Capital market equilibrium with transaction costs. Journal of Political Economy 94, no. 4: 842-862.

Coval, J. D., and T. Shumway. 2001. Expected Option Returns. Journal of Finance 56, no. 3: 983-1009.

Dufour, A., and R. F. Engle. 2000. Time and the price impact of a trade. Journal of Finance 55, no. 6: 2467-2498.

Dufour, A., and M. Nguyen. 2008. Time-varying price discovery in the European Treasury markets. ICMA Centre, University of Reading. Working Paper Series.

Dufour, A., and F. S. Skinner. 2004. MTS time series: Market and data description for the European bond and repo database. ICMA Centre, University of Reading. Working Paper 2004-07. 
Dunne, P. G., M. J. Moore, and R. Portes. 2007. Benchmark status in fixed-income asset markets. Journal of Business Finance and Accounting 34, no. 9-10: $1615-1634$.

Easley, D., S. Hvidkjaer, and M. O'Hara. 2002. Is information risk a determinant of asset returns? Journal of Finance 57, no. 5: 2185-2221.

ECB. 2004. The Euro bond market study. European Central Bank, Frankfurt.

Fama, E. F., and J. D. MacBeth. 1973. Risk, return and equilibrium: Empirical tests. Journal of Political Economy 81, no. 3: 607-636.

Fleming, J. 1998. The quality of market volatility forecasts implied by S\&P 100 index option prices. Journal of Empirical Finance 5, no. 4: 317-345.

Fleming, M. J. 2001. Measuring treasury market liquidity. Working paper 133, Federal Reserve Bank of New York.

Garleanu, N., and L. H. Pedersen. 2004. Adverse selection and the required return. Review of Financial Studies 17, no. 3: 643-665.

Gebhardt, W. R., S. Hvidkjaer, and B. Swaminathan. 2005. The cross-section of expected corporate bond returns: Betas or characteristics. Journal of Financial Economics 75, no. 1: 85-114.

Goldstein, M. A., and A. K. Kavajecz. 2000. Eighths, sixteenths and market depth: Changes in tick size and liquidity provision on the NYSE. Journal of Financial Economics 56, no. 1: 125-149.

Green, C. T. 2004. Economic news and the impact of trading on bond prices. Journal of Finance 59, no. 3: 1201-1234.

Hasbrouck, J. 1991a. Measuring the information content of stock trades. Journal of Finance 46, no. 1: 179-207.

Hasbrouck, J. 1991b. The summary informativeness of stock trades: An econometric analysis. Review of Financial Studies 4, no. 3: 571-595.

Hasbrouck, J. 2003. Intraday price formation in U.S. equity index markets. Journal of Finance 58, no. 6: 2375-2399.

Hasbrouck, J. 2007. Empirical Market Microstructure: The institutions, economics, and econometrics of securities trading. New York: Oxford University Press.

Houweling, P., A. Mentink, and T. Vorst. 2005. Comparing possible proxies of corporate bond liquidity. Journal of Banking and Finance 29, no. 6: 13311358.

IMF. 2001. The changing structure of major government securities markets: implications for private financial markets and key policy issues. International Monetary Fund, Washington.

Ito, T., R. K. Lyons, and M. T. Melvin. 1998. Is there private information in the foreign exchange market? The Tokyo experiment. Journal of Finance 53, no. 3: 1111-1130.

Krishnamurthy, A. 2002. The bond/old-bond spread. Journal of Financial Economics 66, no. 2-3: 463-506.

Li, H., J. Wang, C. Wu, and Y. He. 2009. Are liquidity and information risks priced in the Treasury bond market? Journal of Finance, 64, no. 1: 467-503.

Malz, A. M. 2003. Liquidity risk: Current research and practice. Risk Metrics Group, New York.

Nelson, C. R., and A. F. Siegel. 1987. Parsimonious modeling of yield curves. Journal of Business 60, no.4: 473-489.

O'Hara, M. 2003. Presidential address: Liquidity and price discovery. Journal of Finance 58, no. 4: 1335-1354. 
Pasquariello, P., and C. Vega. 2007. Informed and strategic order flow in the bond markets. Review of Financial Studies 20, no. 6: 1975-2019.

Peiers, B. 1997. Informed traders, intervention, and price leadership: A deeper view of the microstructure of the foreign exchange market. Journal of Finance 52, no. 4: $1589-1614$.

Persaud, A. D. 2006. Improving efficiency in the European government bond market. ICAP plc.

Petersen, M. A. 2009. Estimating standard errors in finance panel data sets: Comparing approaches. Review of Financial Studies 22, no. 1: 435-480.

Vayanos, D. 2004. Flight to Quality, Flight to Liquidity and the Pricing of Risk. NBER Working paper 10327.

Veronesi, P. 1999. Stock market overreaction to bad news in good times: A rational expectation equilibrium model. Review of Financial Studies 12, no. 5: 9751007.

Wang, J. 1993. A model of intertemporal asset prices under asymmetric information. Review of Economic Studies 60, no. 2: 249-282.

\section{Notes}

${ }^{1}$ Dunne et al. (2007) report that the total outstanding amount of the euro-area government bonds is more than 3.9 trillion euro and that their daily secondary market size averages 30 billion euro. The European Central Bank (ECB, 2004) indicates that hedging bond positions is commonly developed on the basis of government bond yields.

${ }^{2}$ Persaud (2006) estimates that MTS accounts for $71.9 \%$ of the electronic trading volume of European cash government bonds.

${ }^{3}$ Several other academic studies use data from the MTS markets (see for example, Codogno et al., 2003; Dunne et al., 2007; Beber et al., 2009).

${ }^{4}$ The European Central Bank (ECB, 2004) indicates that the fixed-rate coupon bonds alone account for $65 \%$ of the euro-area government bonds.

${ }^{5}$ These data are available at www.markit.com.

${ }^{6}$ The Chicago Board Options Exchange's VIX, a similar volatility index in the U.S., is widely known as the "worry gauge" Financial Times, August 25, 2007, page 5. 
Table 1. Descriptive statistics.

\begin{tabular}{llcccrcc}
\hline Country & Rating & $\begin{array}{c}\text { Daily } \\
\text { Observations }\end{array}$ & $\begin{array}{c}\text { No. } \\
\text { Bonds }\end{array}$ & $\begin{array}{c}\text { No. } \\
\text { Trades }\end{array}$ & $\begin{array}{c}\text { Total } \\
\text { Volume }\end{array}$ & $\begin{array}{c}\text { Avg. } \\
\text { Trade } \\
\text { Size }\end{array}$ & $\begin{array}{c}\text { Avg. } \\
\text { Duration }\end{array}$ \\
\hline Austria & AAA & 27,099 & 18 & 21,569 & 188,766 & 8.75 & 5.74 \\
Belgium & AA & 32,778 & 28 & 69,649 & 572,156 & 8.21 & 5.69 \\
Finland & AAA & 14,400 & 9 & 26,995 & 255,433 & 9.46 & 4.26 \\
France & AAA & 66,330 & 60 & 80,138 & 612,652 & 7.64 & 5.37 \\
Germany & AAA & 70,237 & 83 & 88,836 & 600,977 & 6.77 & 4.73 \\
Greece & A & 35,589 & 31 & 77,069 & 581,360 & 7.54 & 5.09 \\
Italy & AA & 68,595 & 68 & 805,902 & $4,474,865$ & 5.55 & 5.84 \\
Netherlands & AAA & 27,744 & 25 & 26,635 & 238,340 & 8.95 & 4.58 \\
Portugal & AA & 34,206 & 19 & 73,795 & 640,548 & 8.68 & 5.09 \\
Spain & AA & 42,716 & 34 & 64,940 & 570,622 & 8.79 & 5.85 \\
\hline
\end{tabular}

Note: We consider fixed-rate and zero-coupon bonds issued by ten euro-area central governments and traded on the MTS markets from April 1, 2003 to September 28, 2007. Rating is the sovereign rating in April 2003. The daily observations are the total number of daily observations contained in our sample for each sovereign bond market. The number of trades is the total number of transactions taking place within MTS trading hours (8:15am-5:30pm CET). Total volume is the cumulative transaction quantity measured in million euros. Trade Size is the average quantity per transaction in million euros. Duration is the weighted maturity (in years) of bond discounted cash flows. 
Table 2. Descriptive statistics by maturity.

\begin{tabular}{|c|c|c|c|c|c|c|c|c|}
\hline Country & $\begin{array}{l}\text { Bond } \\
\text { Yield } \\
(\%)\end{array}$ & $\begin{array}{l}\text { Permanent } \\
\text { Impact } \\
\text { (bps) }\end{array}$ & $\begin{array}{l}\text { Bid-Ask } \\
\text { Spread } \\
\text { (bps) }\end{array}$ & $\begin{array}{l}\text { Depth } \\
\text { (€million) }\end{array}$ & $\begin{array}{l}\text { Coupon } \\
\text { Rate } \\
(\%)\end{array}$ & $\begin{array}{l}\text { Duration } \\
\text { (year) }\end{array}$ & $\begin{array}{l}\text { Parti- } \\
\text { cipants }\end{array}$ & $\begin{array}{l}\text { Tick } \\
\text { Size }\end{array}$ \\
\hline \multicolumn{9}{|c|}{ Panel A: Short maturity group } \\
\hline Austria & 3.04 & 0.26 & 2.33 & 33.06 & 5.05 & 2.06 & 56 & 0.010 \\
\hline Belgium & 2.91 & 0.20 & 1.94 & 26.02 & 5.42 & 2.03 & 35 & 0.007 \\
\hline Finland & 3.19 & 0.20 & 1.94 & 28.59 & 4.01 & 2.28 & 47 & 0.006 \\
\hline France & 3.06 & 0.25 & 2.29 & 25.36 & 4.36 & 2.03 & 41 & 0.008 \\
\hline Germany & 2.88 & 0.23 & 2.09 & 22.47 & 3.97 & 1.90 & 62 & 0.006 \\
\hline Greece & 3.09 & 0.26 & 2.27 & 23.22 & 4.41 & 2.05 & 42 & 0.007 \\
\hline Italy & 2.96 & 0.17 & 1.54 & 33.80 & 4.40 & 1.94 & 92 & 0.008 \\
\hline Netherlands & 3.04 & 0.23 & 2.07 & 23.28 & 3.81 & 2.03 & 44 & 0.005 \\
\hline Portugal & 3.01 & 0.22 & 2.09 & 35.87 & 4.17 & 2.08 & 49 & 0.008 \\
\hline Spain & 2.96 & 0.22 & 1.95 & 30.59 & 4.00 & 2.01 & 43 & 0.006 \\
\hline \multicolumn{9}{|c|}{ Panel B: Medium maturity group } \\
\hline Austria & 3.44 & 0.41 & 3.24 & 26.23 & 4.76 & 4.87 & 56 & 0.010 \\
\hline Belgium & 3.47 & 0.32 & 2.86 & 26.99 & 5.04 & 4.87 & 36 & 0.010 \\
\hline Finland & 3.35 & 0.38 & 2.69 & 31.52 & 4.59 & 4.77 & 46 & 0.010 \\
\hline France & 3.47 & 0.42 & 3.22 & 23.02 & 4.45 & 4.83 & 41 & 0.010 \\
\hline Germany & 3.43 & 0.50 & 2.86 & 25.95 & 4.31 & 4.74 & 62 & 0.010 \\
\hline Greece & 3.60 & 0.45 & 3.22 & 24.42 & 5.03 & 4.96 & 42 & 0.010 \\
\hline Italy & 3.53 & 0.36 & 2.31 & 36.10 & 4.44 & 4.65 & 90 & 0.010 \\
\hline Netherlands & 3.46 & 0.44 & 3.04 & 28.71 & 4.25 & 5.01 & 46 & 0.010 \\
\hline Portugal & 3.56 & 0.30 & 3.02 & 33.98 & 4.67 & 5.01 & 47 & 0.010 \\
\hline Spain & 3.55 & 0.37 & 2.83 & 28.66 & 4.73 & 5.00 & 42 & 0.009 \\
\hline \multicolumn{9}{|c|}{ Panel C: Long maturity group } \\
\hline Austria & 4.00 & 0.93 & 7.36 & 15.28 & 4.44 & 9.85 & 57 & 0.010 \\
\hline Belgium & 4.04 & 0.67 & 6.07 & 19.64 & 4.93 & 9.96 & 39 & 0.010 \\
\hline Finland & 3.93 & 0.58 & 3.28 & 29.11 & 4.64 & 7.91 & 46 & 0.010 \\
\hline France & 4.00 & 1.04 & 6.58 & 15.72 & 4.57 & 10.13 & 44 & 0.010 \\
\hline Germany & 3.95 & 1.32 & 6.24 & 20.13 & 4.58 & 10.30 & 64 & 0.010 \\
\hline Greece & 4.21 & 0.80 & 5.49 & 16.95 & 5.30 & 9.37 & 42 & 0.010 \\
\hline Italy & 4.31 & 0.88 & 6.33 & 16.24 & 5.17 & 11.10 & 91 & 0.010 \\
\hline Netherlands & 4.00 & 0.79 & 6.08 & 21.44 & 4.53 & 9.16 & 48 & 0.010 \\
\hline Portugal & 4.05 & 0.65 & 5.65 & 22.84 & 4.32 & 9.40 & 49 & 0.010 \\
\hline Spain & 4.00 & 0.84 & 6.00 & 19.24 & 4.97 & 10.13 & 42 & 0.010 \\
\hline
\end{tabular}

Note: We present summary statistics for our sample sovereign bonds grouped by maturity and nationality of the issuer. We first classify bonds based on their nationality. We then split the sample into six month sub-periods and at the beginning of each sub-period we assign bonds to three different maturity groups (short, medium and long) using the 30:40:30 break points of the ranked duration. Permanent price impacts are estimated over each six month sub-period using VAR models for quote changes and net order flows. 
Table 3. Cross-sectional correlation coefficients.

\begin{tabular}{lllllll}
\hline & $\begin{array}{l}\text { Permanent } \\
\text { Impact }\end{array}$ & $\begin{array}{l}\text { Bid-ask } \\
\text { Spread }\end{array}$ & Depth & Duration & Participants & $\begin{array}{c}\text { Tick } \\
\text { Size }\end{array}$ \\
\hline Permanent Impact & 1 & & & & & \\
Bid-ask Spread & 0.3 & 1 & & & & \\
Depth & -0.17 & -0.55 & 1 & & & \\
Duration & 0.33 & 0.88 & -0.53 & 1 & & \\
Participants & 0 & -0.01 & 0.04 & 0.04 & 1 & \\
Tick Size & 0.14 & 0.28 & 0.23 & 0.42 & -0.02 & 1 \\
\hline
\end{tabular}

Note: This table presents the cross-sectional correlation coefficients between the variables used in our asset pricing tests. 
Table 4. Permanent trading impacts and seasonedness.

Panel A: Average permanent trading impact by maturity and seasonedness

\begin{tabular}{lllllll}
\hline Seasonedness & 2-year & 5 -year & 10-year & 15-year & 20-year & 30-year \\
\hline On-the-run & 0.25 & 0.38 & 0.75 & 0.80 & 1.26 & 1.43 \\
Just-off-the-run & 0.17 & 0.34 & 0.62 & 0.78 & 1.24 & 1.33 \\
Off-the-run & 0.23 & 0.32 & 0.54 & 0.71 & 0.85 & 1.34 \\
\hline
\end{tabular}

Panel B: Tests on the cumulative distributions of permanent trading impacts

\begin{tabular}{lll}
\hline Null Hypothesis & Kruskal-Wallis test & Wilcoxon test \\
\hline On= just-off=off-the-run & $53.82(0.001)$ & \\
On $=$ Just-off -the-run & & $2.63(0.001)$ \\
On $=$ off-the-run & & $7.20(0.001)$ \\
\hline
\end{tabular}

Note: We split the sample into 6 months sub-periods. On the first day of every subperiod we sort our sample bonds in terms of how recently they have been issued and form three distinct categories of seasonedness: on-the-run, just-off-the-run and offthe-run. This classification is performed for bonds belonging to various maturity buckets: 2 (1-2 years), 5 (2-5 years), 10 (5-10 years), 15 (10-15 years), 20 (15-20 years) and 30 (20-30 years). For each maturity bucket, the on-the-run group includes bonds that have been classified as the most recently-issued bonds within the previous six month window. Just-off-the-run bonds have between six months and two years from the issue date whereas off-the-run bonds have more than two years from the issue date. We then examine the significance of the cross-sectional differences in the permanent trading impacts for these groups. The Kruskal-Wallis test examines the null hypothesis that the trading impacts of all of the bond groups are drawn from the same distribution. The Wilcoxon rank-sum test investigates the null hypothesis that the median difference in price impacts between the two sample groups is zero versus the alternative hypothesis that one group has higher price impacts. We report the test statistics and the $p$-values (in parentheses). 
Table 5. Cross-country differences in permanent trading impacts.

Panel A: short maturity group

\begin{tabular}{lcc}
\hline Null Hypothesis & Kruskal-Wallis test & Wilcoxon test \\
\hline $\mathrm{DE}=\mathrm{FR}=\mathrm{IT}=\mathrm{ES}$ & $51.043(0.001)$ & \\
$\mathrm{FR}=\mathrm{DE}$ & & $0.414(0.329)$ \\
$\mathrm{FR}=\mathrm{IT}$ & & $5.992(0.001)$ \\
$\mathrm{FR}=\mathrm{ES}$ & $1.668(0.047)$ \\
\hline
\end{tabular}

Panel B: medium maturity group

\begin{tabular}{llc}
\hline Null Hypothesis & Kruskal-Wallis test & Wilcoxon test \\
\hline $\mathrm{DE}=\mathrm{FR}=\mathrm{IT}=\mathrm{ES}$ & $21.788(0.001)$ & \\
$\mathrm{FR}=\mathrm{DE}$ & & $0.998(0.160)$ \\
$\mathrm{FR}=\mathrm{IT}$ & & $4.037(0.001)$ \\
$\mathrm{FR}=\mathrm{ES}$ & $1.250(0.105)$ \\
\hline
\end{tabular}

Panel C: long maturity group

\begin{tabular}{lll}
\hline Null Hypothesis & Kruskal-Wallis test & Wilcoxon test \\
\hline DE $=$ FR=IT=ES & $21.710(0.001)$ & \\
FR $=$ DE & & $2.870(0.002)$ \\
FR $=$ IT & & $3.750(0.001)$ \\
FR $=$ ES & $4.568(0.001)$ \\
\hline
\end{tabular}

Note: We split the sample into six month sub-periods. On the first day of every subperiod we sort bonds into three maturity groups (short, medium and long) using the 30:40:30 break points of the ranked duration. We focus on the sovereign bonds from Germany (DE), France (FR), Italy (IT) and Spain (ES) and investigate cross-country differences in the permanent trading impacts for each maturity group. The KruskalWallis test and Wilcoxon rank-sum test are described in Table 4. We provide test statistics and $p$-values (in parentheses). 
Table 6. Cross-sectional regressions.

\begin{tabular}{llll}
\hline Variables & AAA bonds & AA-A bonds & All Bonds \\
\hline AA & & & $0.060(40.88)$ \\
A & & $0.074(49.02)$ & $0.143(79.56)$ \\
Permanent Impact & $0.004(3.96)$ & $0.042(7.38)$ & $0.003(2.33)$ \\
Bid-ask Spread & $0.006(21.34)$ & $0.009(11.35)$ & $0.008(27.42)$ \\
Depth & $-0.007(-7.59)$ & $-0.032(-22.72)$ & $-0.023(-24.29)$ \\
Coupon rate & $0.006(23.93)$ & $0.004(15.88)$ & $0.005(24.28)$ \\
Tick & $7.939(14.74)$ & $20.528(37.57)$ & $13.724(26.29)$ \\
Participants $(\times 10)$ & $-0.00(-1.30)$ & $0.008(22.05)$ & $0.006(21.59)$ \\
\hline Adjusted R-square & 0.501 & 0.639 & 0.629 \\
\hline
\end{tabular}

Note: This table presents the averages of the cross-sectional coefficients and the Newey-West adjusted $t$-statistics (in parentheses) obtained from the cross-sectional regressions estimated over the period from October 1, 2003 to September 28, 2007. Our dependent variable is the swap spread or the difference between the daily closing sovereign bond yield and the corresponding swap rate estimated from the Nelson and Siegel term structure of the swap rates. The explanatory variables include the intercept, the permanent trading impact, the two rating dummies (AA equals 1 if the bond has AA rating and zero otherwise; whereas A equals 1 if the bond is rated $\mathrm{A}$ and zero otherwise), the bid-ask spread, the market depth, the daily number of participants for a particular bond, the tick size and the coupon rate. Permanent price impacts are estimated over six month sub-periods using VAR models for quote changes and net order flows. Lagged permanent price impacts are used in the cross-sectional regressions. 
Table 7. Information asymmetry and market uncertainty.

Panel A: Equity market uncertainty

\begin{tabular}{llll}
\hline Variables & Normal & Abnormal & Abnormal - Normal \\
\hline AA & $0.062(12.03)$ & $0.061(14.4)$ & $-0.000(-10.54)$ \\
A & $0.150(19.61)$ & $0.139(83.22)$ & $-0.011(-5.84)$ \\
Permanent Impact & $0.002(1.87)$ & $0.008(4.18)$ & $0.006(12.47)$ \\
Bid-ask Spread & $0.008(20.91)$ & $0.01(13.42)$ & $0.002(10.05)$ \\
Depth & $-0.021(-10.74)$ & $-0.023(-8.04)$ & $-0.002(-11.65)$ \\
Coupon rate & $0.007(22.93)$ & $0.011(9.13)$ & $0.004(11.50)$ \\
Tick & $13.452(24.76)$ & $11.861(7.95)$ & $-1.591(0.46)$ \\
Participants $(\times 10)$ & $0.006(11.39)$ & $0.003(3.06)$ & $-0.004(-6.03)$ \\
\hline Adjusted R-square & 0.621 & 0.579 & \\
\hline
\end{tabular}

Panel B: Interest rate uncertainty

\begin{tabular}{llll}
\hline Variables & Normal & Abnormal & Abnormal - Normal \\
\hline AA & $0.064(8.84)$ & $0.061(60.4)$ & $-0.003(-3.27)$ \\
A & $0.142(72.97)$ & $0.124(174.19)$ & $-0.018(-7.49)$ \\
Permanent Impact & $0.000(0.26)$ & $0.016(9.63)$ & $0.016(10.34)$ \\
Bid-ask Spread & $0.008(62)$ & $0.014(8.47)$ & $0.006(7.09)$ \\
Depth & $-0.025(-53.26)$ & $-0.026(-2.47)$ & $-0.001(8.60)$ \\
Coupon rate & $0.006(38.57)$ & $0.01(29.75)$ & $0.004(6.55)$ \\
Tick & $13.152(52.86)$ & $14.077(37.68)$ & $0.925(10.65)$ \\
Participants $(\times 10)$ & $0.006(49.2)$ & $0.007(2.19)$ & $0.001(2.32)$ \\
\hline Adjusted R-square & 0.65 & 0.414 & \\
\hline
\end{tabular}

Note: This table presents the average of the cross-sectional coefficients and the Newey-West adjusted $t$-statistics (in parentheses) obtained for days with different levels of market uncertainty. Equity market uncertainty is captured by the vStoxx index which indicates the near term volatility embedded in the option prices of the Dow Jones Euro Stoxx 50 equity index. Interest rate uncertainty is measured by the implied volatility obtained from swaption prices (the one-month option contract on one-year Euro swap rate). We define days with abnormal market uncertainty as those days where the implied volatility of either the bond or equity market is one standard deviation above the mean. The days when this condition does not hold are classified as normal. We run the cross-sectional regressions described in Table 6 separately on each of these two sub-samples. We use the pair-wise Wilcoxon test to examine whether the coefficients obtained for the abnormal periods are significantly higher than those estimated for the normal periods. 
Table 8. Cross-sectional regressions with country dummy variables

\begin{tabular}{llll}
\hline Variables & Whole Sample & $\begin{array}{l}\text { Abnormal Equity } \\
\text { Market Uncertainty }\end{array}$ & $\begin{array}{l}\text { Abnormal Interest } \\
\text { Rate Uncertainty }\end{array}$ \\
\hline Austria & $0.005(2.33)$ & $0.041(15.53)$ & $0.056(42.3)$ \\
Belgium & $0.027(11.02)$ & $0.067(17.39)$ & $0.064(47.51)$ \\
Finland & $0.029(11.87)$ & $0.072(20.99)$ & $0.067(57.92)$ \\
France & $0.001(5.13)$ & $0.022(9.69)$ & $0.036(32.41)$ \\
Greece & $0.138(64.3)$ & $0.178(41.93)$ & $0.177(8.15)$ \\
Italy & $0.142(53.36)$ & $0.166(32.81)$ & $0.163(62.29)$ \\
Netherlands & $0.032(15.42)$ & $0.065(28.09)$ & $0.073(69.67)$ \\
Portugal & $0.085(40.70)$ & $0.124(48.19)$ & $0.110(65.09)$ \\
Spain & $0.025(11.68)$ & $0.062(13.93)$ & $0.042(18.66)$ \\
Permanent Impact & $0.006(4.21)$ & $0.018(6.86)$ & $0.037(16.69)$ \\
Bid-ask Spread & $0.006(26.21)$ & $0.008(21.09)$ & $0.010(5.97)$ \\
Depth & $-0.029(-26.71)$ & $-0.029(-14.36)$ & $-0.020(-3.21)$ \\
Coupon rate & $0.006(24.20)$ & $0.008(23.25)$ & $0.009(24.69)$ \\
Tick & $15.728(29.38)$ & $16.632(20.89)$ & $18.118(50.13)$ \\
Participants $(\times 10)$ & $-0.000(-0.99)$ & $-0.000(-0.49)$ & $0.003(0.79)$ \\
\hline Adjusted R-square & 0.685 & 0.643 & 0.473
\end{tabular}

Note: This table presents the averages of the cross-sectional coefficients and the Newey-West adjusted $t$-statistics (in parentheses) obtained from cross-sectional regressions. To capture the country effects we use country dummy variables. For instance, the Italy dummy variable equals one for Italian bond observations and zero otherwise. Since the German bonds serve as the benchmark, the Italy dummy variable captures the average yield spread between German and Italian bonds. We perform the cross-sectional regressions over the whole sample period from October 1, 2003 to September 28, 2007. We average the estimated coefficients over the whole sample and over days with abnormal equity and bond market uncertainty. We define days with abnormal market uncertainty as those days where the implied volatility of either the bond or equity market is one standard deviation above the mean. 
Table 9. Robustness.

\begin{tabular}{llll}
\hline Variables & AAA bonds & AA-A bonds & All Bonds \\
\hline AA & & & $0.068(40.52)$ \\
A & & $0.074(45.6)$ & $0.143(83.54)$ \\
Permanent Impact & $0.02(6.03)$ & $0.161(20.22)$ & $0.028(7.24)$ \\
Bid-ask Spread & $0.005(21.71)$ & $0.006(12.46)$ & $0.007(33.15)$ \\
Depth & $-0.005(-5.3)$ & $-0.021(-14.56)$ & $-0.02(-17.48)$ \\
Coupon rate & $0.007(23.09)$ & $0.006(20.03)$ & $0.008(24.15)$ \\
Tick & $7.234(15.66)$ & $14.706(24.12)$ & $12.524(25.01)$ \\
Participants $(\times 10)$ & $-0.000(-1.24)$ & $0.006(31.54)$ & $0.006(22.47)$ \\
\hline Adjusted R-square & 0.533 & 0.694 & 0.629 \\
\hline
\end{tabular}

Note: This table presents the average of the cross-sectional coefficients and the Newey-West adjusted $t$-statistics (in parentheses) obtained from the cross-sectional regressions described in Table 6 . Instead of using bond specific permanent trading impacts as a regressor, we compute the equally-weighted portfolio averages of the permanent trading impacts. Bond portfolios are formed by splitting the sample into 6 month sub-periods and by partitioning the data of every sub-period along two dimensions: nationality of the issuer and bond maturity. In particular, we have ten nationality groups and three maturity groups (short, medium and long) computed using the 30:40:30 break points of the ranked duration. Thus, our data are partitioned into 30 portfolios. 
Figure 1. Permanent trading impacts.
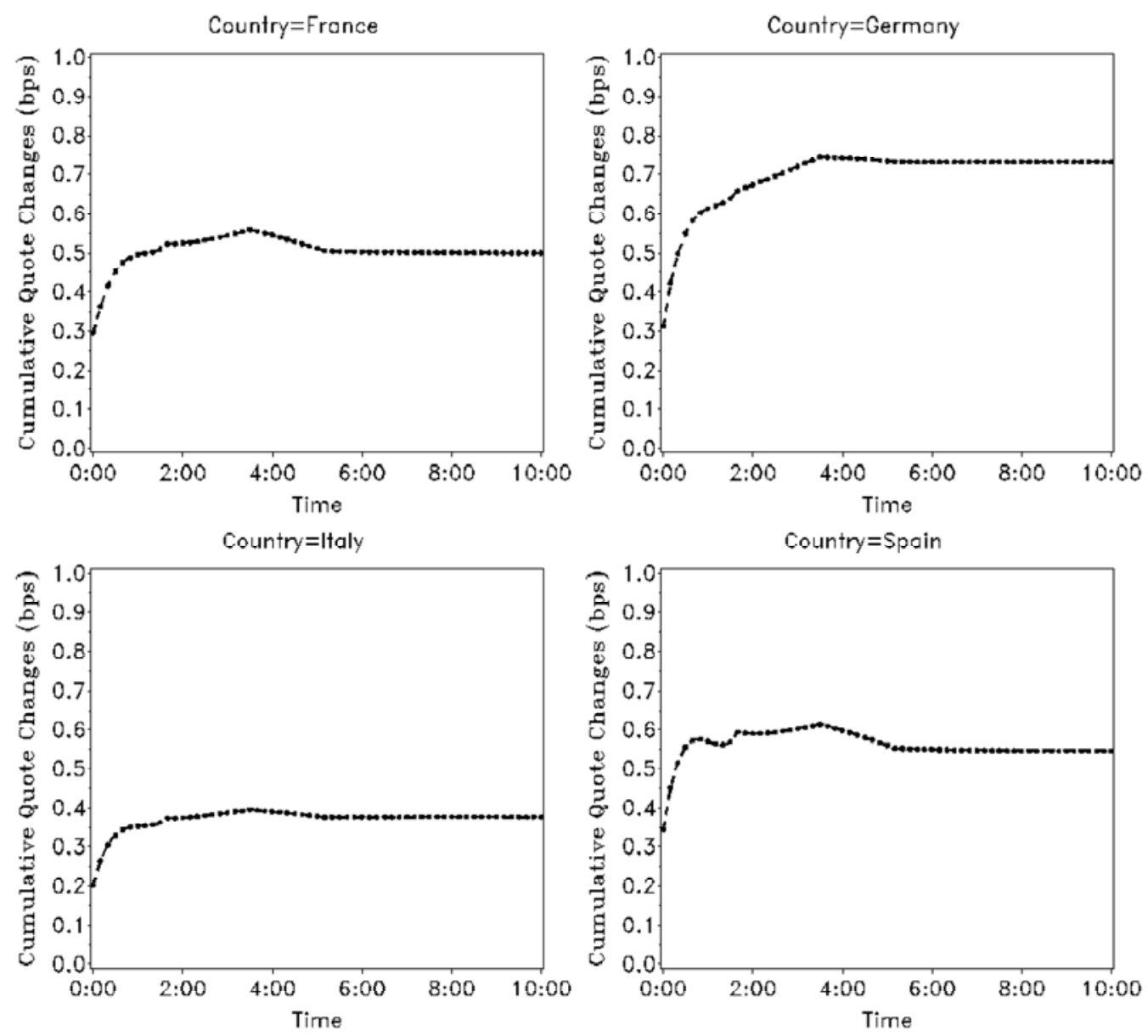

Note: This figure exhibits the cumulative mid-quote price changes in calendar time (minutes: seconds) of the German, French, Italian and Spanish sovereign bonds after an initial unexpected purchase order with an average trade size. Hasbrouck's (1991a) VAR is estimated in calendar time for the most-recently issued 10-year bonds over the period from April 1, 2003 to September 30, 2003. 
Figure 2. Seasonedness and permanent trading impacts.

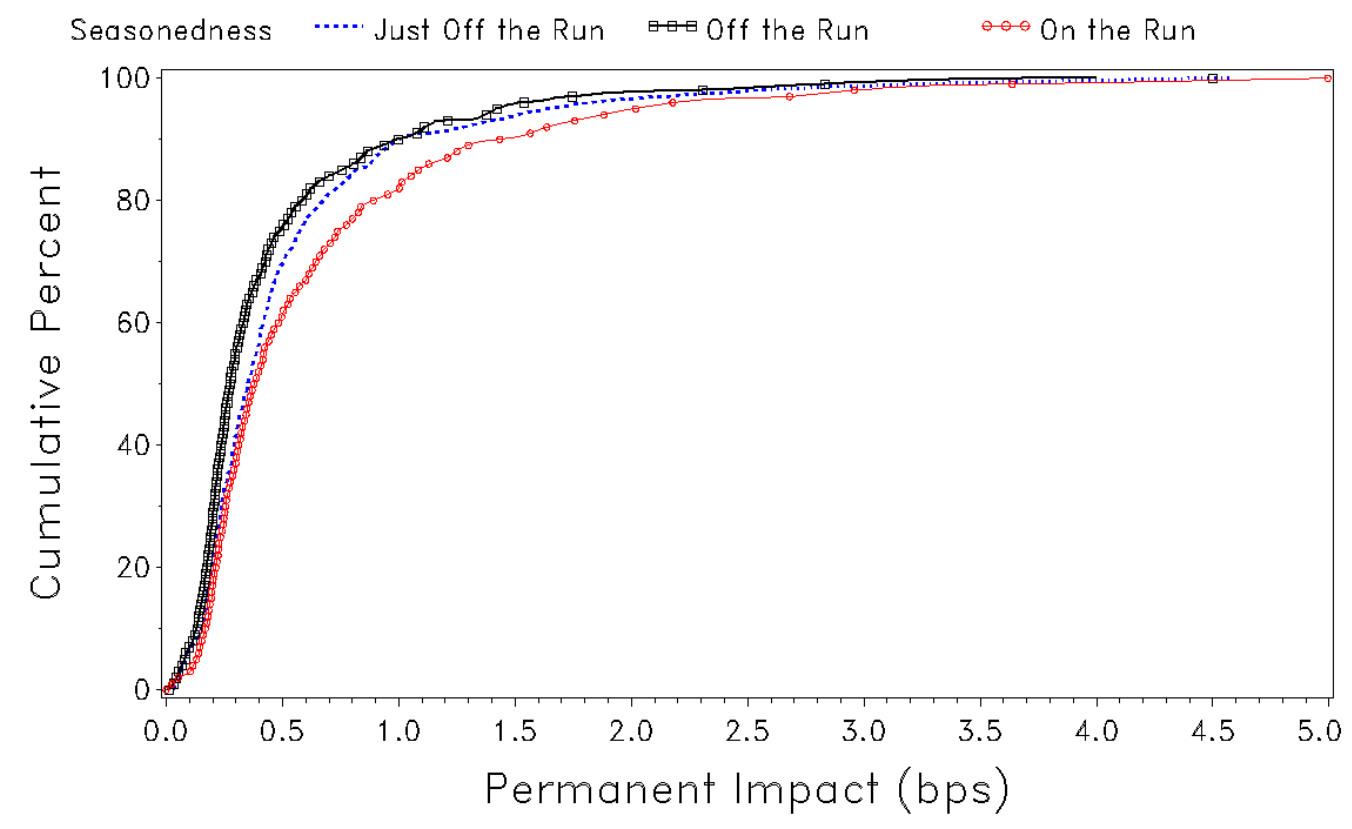

Note: This figure presents the cumulative distribution functions of the permanent trading impacts for three seasonedness groups. The on-the-run group includes the bonds that have been classified as the most recently-issued bonds within the past six months for each of the maturity buckets: 2 (1-2 year), 5 (2-5 year), 10 (5-10 year), 15 (10-15 year), 20 (15-20 year) and 30 (20-30 year). Furthermore, just-off-the-run bonds have between six months and two years from the issue date whereas off-the-run bonds have more than two years from the issue date. 
Figure 3. Cross-country differences in permanent trading impacts.

Panel A: Short maturity group

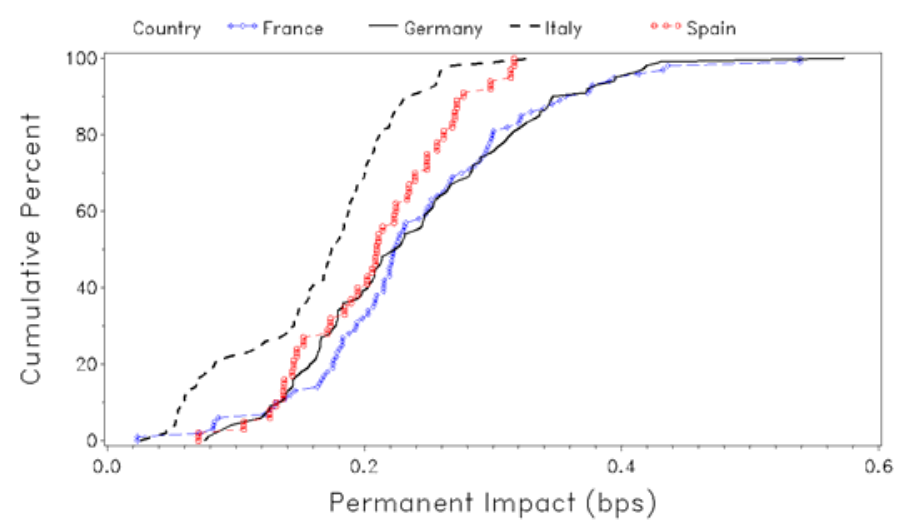

Panel B: Medium maturity group

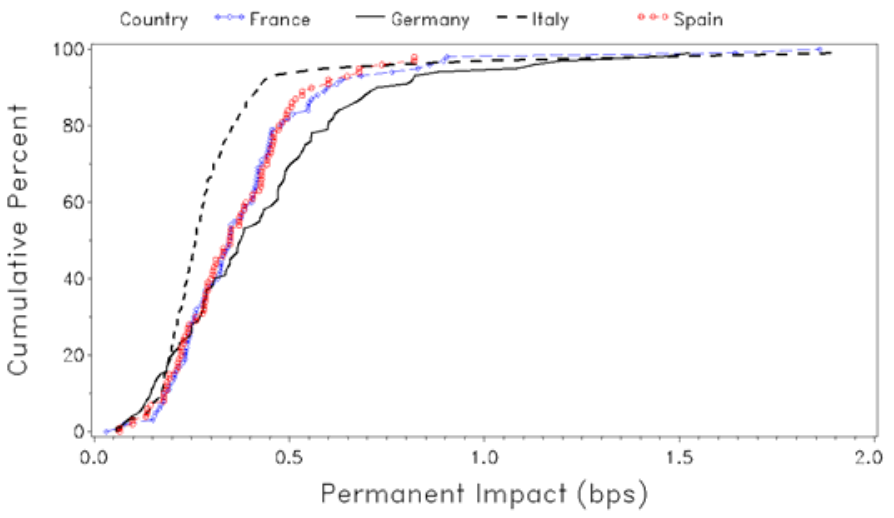

Panel C: Long maturity group

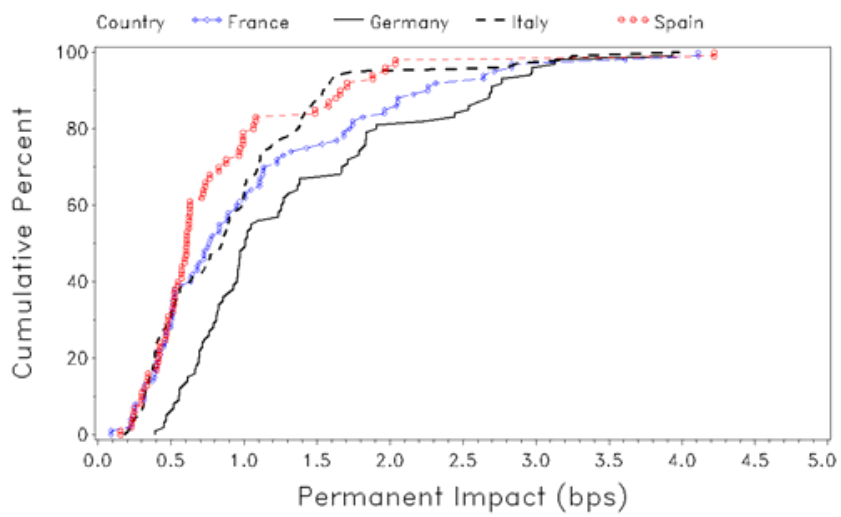

Note: This figure presents the cumulative distribution functions of the permanent trading impacts for the German, French, Italian and Spanish sovereign bonds. We sort these bonds every six months into three maturity groups (short, medium and long) using the 30:40:30 break points of the ranked duration. 